\title{
NICOLAS LÉMERY (1645-1715) Y SU TEORÍA FÍSICO-QUÍMICA SOBRE DIVERSOS FENÓMENOS DE INTERÉS PARA LAS CIENCIAS DE LA TIERRA
}

\author{
Nicolas Lémery (1645-1715) and his Physical-chemical \\ Theory about Different Phenomena for Earth Sciences
}

\author{
Cándido Manuel GARCÍA CRUZ \\ INHIGEO (International Commission on the History of the Geological Sciences) \\ candidomgc@gmail.com
}

Fecha de recepción: 9/11/2014

Fecha de aceptación defintiva: 10/5/2015

RESUMEN: Se presenta por primera vez en castellano la traducción íntegra de un trabajo del químico y boticario francés Nicolas Lémery (1645-1715), donde intenta explicar sobre una base físico-química diversos fenómenos de interés para las Ciencias de la Tierra, como los terremotos, los fuegos subterráneos, los huracanes, los rayos y el trueno. Esta explicación tenía una causa común para todos los fenómenos citados: los procesos de fermentación mineral, en este caso del azufre y del hierro, como fuente de liberación de calor, dentro de la teoría corpuscular de la materia y la filosofía mecanicista, y asimismo constituye una interesante aportación de la influencia de la química en el desarrollo incipiente de la geología experimental en los albores del siglo XVIII.

Palabras clave: Nicolas Lémery; explicación físico-química; terremotos; fuegos subterráneos; huracán; rayo; trueno; Ciencias de la Tierra.

ABSTRACT: An unabridged translation of a work of Nicolas Lémery (16451715) is presented for the first time in Spanish, wherein this French chemist and apothecary attempts an explanation on physical and chemical basis of several significant phenomena in Earth Sciences, such as earthquakes, subterranean fires, 
hurricanes, lightning and thunder. This explanation had a common cause for all the aforementioned phenomena: the processes of mineral fermentation, in this case of sulfur and iron, as a heat source, within the corpuscular theory of matter and mechanistic philosophy, and likewise it represents an interesting contribution of the influence of chemistry on the incipient development of experimental geology at the dawn of the $18^{\text {th }}$ Century.

Kew words: Nicolas Lémery; Physicochemical explanation; Earthquakes; Subterranean fires; Hurricane; Lightning; Thunder; Earth Sciences.

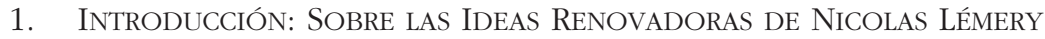

En 2015 se cumplen trescientos años del fallecimiento de Nicolas Lémery (1645-1715), uno de los químicos franceses más relevantes de finales del siglo XVII y principios del XVIII.

Había nacido en Ruan, el 17 de noviembre de $1645^{1}$, y a pesar de su formación original como boticario y médico, al igual que muchos otros científicos de esa época, sus trabajos más importantes los desarrolló en el campo de la química, que se suele considerar como disciplina científica ya desde finales del siglo XVI, puesto que había adquirido un corpus doctrinal propio, ajeno a la farmacia y por lo tanto independiente de sus aplicaciones prácticas ${ }^{2}$. Bajo una tradición orientada en la didáctica, Lémery realizó unas aportaciones altamente novedosas especialmente en relación con la enseñanza y con experiencias de laboratorio que atrajeron la atención de numerosas personas con un cierto nivel cultural, tanto de profesionales con un claro trasfondo socioeconómico como de simples curiosos,

1. La mayoría de los tratados sobre historia de la química suelen abordar, con mayor o menor extensión, la vida y la obra de Nicolas Lémery. Sin embargo, las fuentes más importantes siguen siendo tres trabajos clásicos: Fontenelle, Bernard Le Bovier de. "Éloge de M. Lémery». Histoire de l'Académie Royale des Sciences, Année M.DCCXV, avec les Mémoires de Mathématiques et de Physique pour la même année. Paris: Imprimerie Royale, 1715, pp. 73-82 (publicado en 1717) [reproducido en Euvres diverses de M. de Fontenelle. La Haya: Gosse \& Neaulme, tomo III (nouvelle édition, 1729), pp. 186-193]; TonNet, Joseph. Notice sur Nicolas Lémery, chimiste. (Mémoire présenté à l'Académie Royale de Rouen, pour le concours de l'an 1838). Niort: Académie Royale de Rouen, 1840, 42 pp.; CAP, Paul-Antoine. Études biographiques pour servir à l'histoire des sciences. Première Série: ChimistesNaturalistes. Paris: Victor Masson, 1857, pp. 180-226; véanse, además, Blas y Álvarez, Luis. Biografías y descubrimientos químicos. Madrid: Aguilar, 1947, pp. 127-128; BougARD, Michel. La Chimie de Nicolas Lemery. Turnhout: Brepols, 1999, cap. I; DorvEAux, Paul. "Apothicaires membres de l'Académie Royale des Sciences. VI. Nicolas Lémery». Revue d'Histoire de la Pharmacie, 1931, 19, pp. 208-219; HaNnAWAY, Owen. "Lémery, Nicolas». En GillispIe, Charles Coulston (ed.). Dictionary of Scientific Biography. New York: Charles Scribner, 1981, vol. 8, pp. 172-175.

2. Véanse al respecto Christie, John R.R. y Golinski, Jan V. "The spreading of the word: new directions in the historiography of chemistry 1600-1800". History of Science, 1982, 20, pp. 235-266; HaNNAWAY, Owen. The chemists and the word: The didactics origins of chemistry. Baltimore (MD): Johns Hopkins University Press, 1975, cap. 7; véase más adelante, la nota 16. 
en los inicios de un siglo donde las ciencias físico-químicas habían convertido los laboratorios en gran medida en escenario de espectáculos ${ }^{3}$.

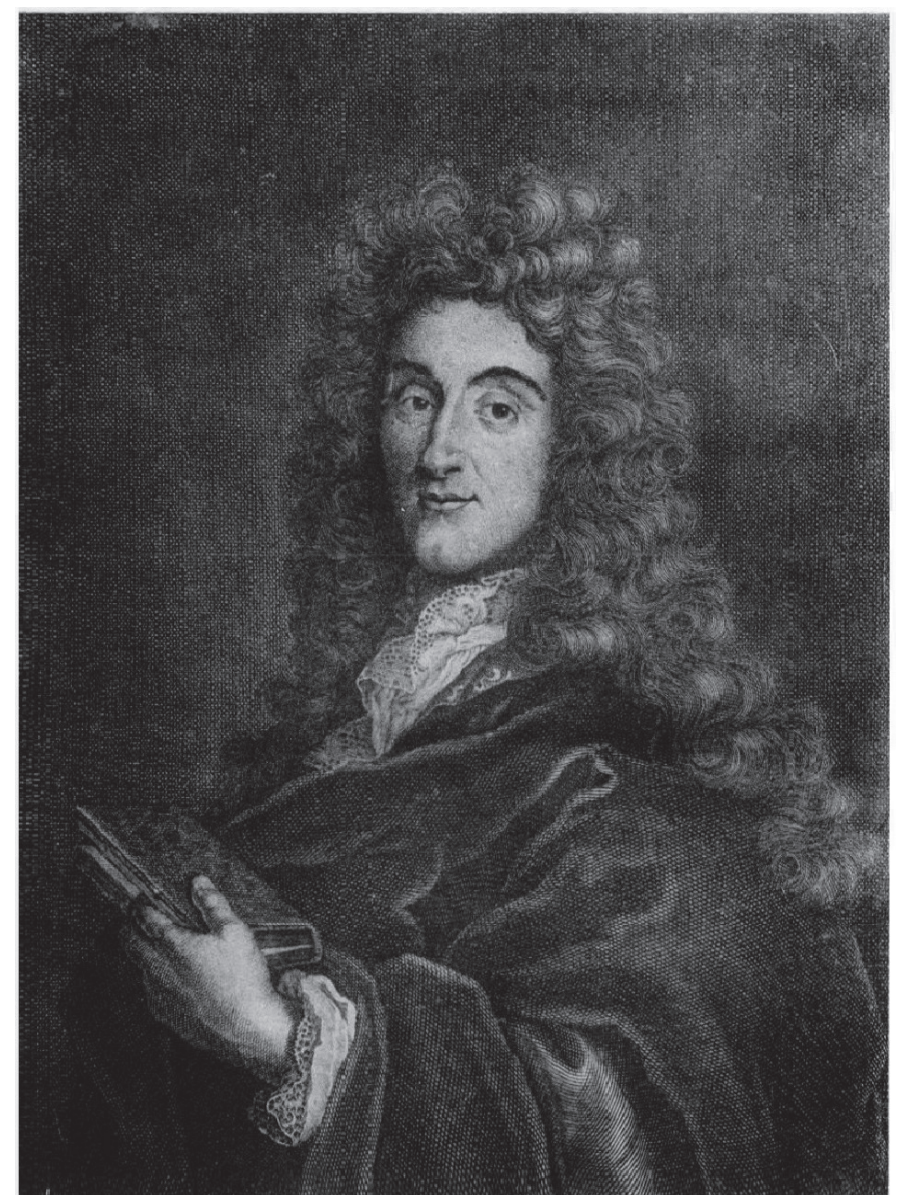

Figura 1. Nicolas Lémery (1645-1715) (en Pharmacopée universelle, 4. ${ }^{a}$ ed./1764, tomo I, frontispicio). [Bibliothèque National de France, París].

3. Véase, por ejemplo, Bensaude-Vincent, Bernadette y Blondel, Christine (eds.). Science and spectacle in the European Enlightenment. Aldershot: Ashgate, 2008, 176 pp. (especialmente, caps. 1, 2, 7 y 9); Boutin, Pierre. "Spectacle en ville: l'expulsion du Dieu vengeur du "Volcan de Lémery». En Bertrand, Dominique, Rieutort, Laurent y Thouret, Jean-Claude (eds.). Villes et volcans. ClermontFerrand: Presses Universitaires Blaise-Pascal, 2009, pp. 175-181. 
Su obra fundamental, Cours de Chymie, apareció por primera vez en $1675^{4}$, con treinta y una ediciones corregidas y aumentadas hasta $1756^{5}$, trece de ellas en vida de su autor, además de varias traducciones a diferentes idiomas ${ }^{6}$, entre ellos al castellano, en $1703^{7}$. Sus conceptos químicos se sitúan dentro de la tradición modernizadora de los trabajos de Christophe Glaser (1615-1670/1678), Robert Boyle (1627-1691), y Sebastien Matte La Faveur (1626-1714). Su ruptura con la alquimia y la crisopeya, con una fuerte tendencia materialista ajena a la economía de la hipótesis divina, estaba enraizada en la teoría corpuscular de Pierre Gassendi (1592-1655), con una amplia base también en las ideas filosóficas de René Descartes (1596-1650) y su mecanicismo racionalista ${ }^{8}$. Lémery publicó además otras

4. LÉmery, Nicolas. Cours de Chymie. Paris: Chez l'Autheur, 1675, 578 pp.

5. Esta edición (París: Jean-Thomas Herissant, 1756, XXV+782 pp.), revisada, corregida y aumentada bajo la dirección de Théodore Baron d'Henouville, está considerada la más completa; fue reimpresa por última vez en París por Charles-Maurice d'Houry, en 1757.

6. Las versiones a otros idiomas fueron al inglés (A course of chymistry: 1677, 1686, 1698, 1720), holandés (Het philosoophze laboratorium, oft' Der chymisten stook-buis: 1683, 1691, 1704), alemán (Cours de chymie, oder: Der vollkommene Chymist: 1698, 1705, 1713, 1726, 1734, 1754), italiano (Corso di Chimica: 1695, 1697, 1700, 1716, 1719), y latín (Cursus chymicus: 1681), y cuatro al castellano (véase la nota siguiente).

7. La primera edición castellana fue Curso chymico. Madrid: J. Garcia Infançon (trad. castellana de la $9^{a}$ ed. francesa 1697), 1703, 528 pp., y la utilizaremos como referencia siempre en este trabajo. Se hicieron además otras tres traducciones: dos en Zaragoza (Diego de Larumbe, 1707 y 1710), y una en Madrid (Manuel Roman, 1721). Las ediciones de 1707 y 1710 incluían el Florigelio theorico-practico, Nuevo curso quimico, de Joseph Assin y Palacios de Ongoz, que fue publicado como obra independiente por Antonio Gonçalez de Reyes (Madrid, 2. ${ }^{a}$ impr. 1712).

8. Sobre las raíces corpusculares y mecanicistas de la química lemeriana, véanse BENSAUDEVincent, Bernardette y STEngers, Isabelle. Histoire de la Chimie. París: La Découverte, 1993, pp. 47-49; Bertomeu SÁnchez, José Ramón y García Belmar, Antonio. La revolución química: Entre la historia y la memoria. Valencia: Publicacions de la Universitat de València, 2006, pp. 19-25; BOUGARD, 1999, op. cit., cap. II; BougARD, Michel. "Vers une histoire des sciences «expérimentale»: Analyse de la pratique chimique de Nicolas Lémery (1645-1715)». Chimie nouvelle, 2002, 20(78), pp. 44-49; BOURZAT, Jean Dominique. Lecture contemporaine $d u$ Cours de Chymie de Nicolas Lemery. Lyon: Cosmogone, 2005, pp. 1-32; Carvallo, Sarah. "Chimie et scepticisme: Héritage et ruptures d'une science. Analyse du Chimiste Sceptique, 1661, Robert Boyle». Revue d'Histoire des Sciences, 2002, 55(4), pp. 451492; Clericuzio, Antonio. Elements, principles and corpuscles. A study of atomism and chemistry in the seventeenth century. Dordrecht-Boston: Kluwer, 2000, pp. 170-177; ClericuzIO, Antonio. "Sooty empiricks' and natural philosophers: The status of chemistry in the seventeenth century". Science in Context, 2010, 23(3), pp. 329-350; FrancKowiaK, Rémi. "La chimie du XVII siècle: une question de principes». Methodos, Savoirs et Textes, 2008, 8, pp. 1-43; KIM, Mi Gyung. Affinity, that elusive dream. A genealogy of the chemical revolution. Cambridge (MA): MIT Press, 2003, pp. 52-58; LAFOnT, Olivier. D'Aristote à Lavoisier. Les étapes de la naissance d'une science. París: Ellipses, 1994, cap. 4; METZGER, Hélène. Les doctrines chimiques en France du début du XVIIe à la fin du XVIIIe siècle. París: Blanchard, 1923 (ed. 1969), pp. 229-338; POwERs, John Charles. "Ars sine arte: Nicholas Lemery and the end of Alchemy in the Eighteenth century France». Ambix, 1998, 45, pp. 163-189 [reproducido en DeBus, Allen George (ed.). Alchemy and early modern chemistry: Papers form Ambix. Huddersfield: Jeremy Mills, 2004, pp. 511-537]; POwers, 2012, op. cit., caps. 3 y 7; PrinciPe, Lawrence M. "A revolution nobody noticed? Changes in early eighteenth-century chymistry». En PRINCIPE, Lawrence M. (ed.). New narra- 
NICOLAS LÉMERY (1645-1715) Y SU TEORÍA FÍSICO-QUÍMICA SOBRE DIVERSOS FENÓMENOS...

tres obras importantes dentro de la corriente químico-médica: Pharmacopée universelle (1697), Dictionnaire universel de drogues simples (1698), e, iniciado ya el siglo XVIII, Traité de l'antimoine (1707), que fueron también traducidas a diversos idiomas (ninguna al castellano), así como varias memorias, notas, observaciones, exámenes y explicaciones. Esta obra espagírica de Lémery tuvo una enorme repercusión en el desarrollo tanto de la química como de la farmacia de su época en toda Europa?.

Lémery falleció de apoplejía el 19 de junio de 1715, en París. En su elogio fúnebre, Bernard Le Bovier de Fontenelle (1657-1757), secretario perpetuo de la Académie Royale de Sciences de la capital francesa, proclamaba que su ciencia rompía casi definitivamente con la alquimia, liberándola así de los oscuros misterios en los que había estado envuelta hasta entonces, con un lenguaje incomprensible y enigmático que describía operaciones y procesos accesibles solo para iniciados ${ }^{10}$. Lémery consiguió abolir este lenguaje hermético, y despojar a la química de la falsa dignidad propia de una casta sacerdotal, reduciendo sus fundamentos a lo más básico y sencillo ${ }^{11}$. Una muestra de ello es la utilización de la palabra destilación en lugar de rectificación, que aún teniendo el mismo significado, este último término poseía ciertas connotaciones morales tal y como se suele apreciar en el sentido que se le da a veces a la interpretación de la forma latina de vitriolo (vitriol), acrónimo de "Visita interiora terrae rectificando invenies occultum lapidem», que significa "visita el interior de la tierra y rectificando

tives in eighteenth-century chemistry. Contributions from the First Francis Bacon Workshop (21-25 April/2005). Dordrecht: Springer, 2007, pp. 1-22 (pp. 3-7); SIEGFRIED, Robert. From elements to atoms: A history of chemical composition. Filadelfia (PA): American Philosophical Society (Transactions, vol. 94, parts 4-6), 2002, cap. 3; WISNIAK, Jaime. "Nicolas Lémery». Revista CENIC, Ciencias Químicas, 2005, 36(2), pp. 123-130.

9. Véanse, por ejemplo, en relación con el desarrollo de la farmacopea hispano-lusa, FOLCH JOU, Guillermo y FRANCES CAUSAPE, M. ${ }^{\text {a }}$ Carmen. "L'influence de Nicolas Lémery dans la pharmacie espagnole». Veröffentlichungen der Internationalen Gesellschaft für Geschichte der Pharmazie, 1975, 42, pp. 49-54; SOuSA Dias, José Pédro y Rõcha PiTA, João Luis. "L'influence de la pharmacie et de la chimie françaises au Portugal au XVIIIe siècle: Nicolas Lémery». Revue d'Histoire de la Pharmacie, 1994, 41(300), pp. 84-90.

10. A pesar de los aspectos críticos de Lémery y otros autores, no se dio en esa época una distinción radical entre química y alquimia, tal y como muestran algunos estudios recientes; véanse, por ejemplo, Golinski, Jan V. "Science in the Enlightenment, revisited». History of Science, 2011, 49(163), 217-231; Joly, Bernard. "À propos d'une prétendue distinction entre la chimie et l'alchimie au XVII ${ }^{\mathrm{e}}$ siècle: Questions d'histoire et de méthode». Revue d'Histoire des Sciences, 2007, 60(1), 167-184; PRINCIPE, Lawrence M. "Transmuting chymistry into chemistry: Eighteenth-Century Chrysopoeia and its repudiation". En Bertomeu-Sánchez, José R., Burns, Duncan T. y VAn Tieggelen, Brigitte (eds.). Neighbours and territories: The evolving identity of chemistry ( $6^{\text {th }}$ International Conference on the History of Chemistry Proceedings, 28 août-1 ${ }^{\mathrm{er}}$ septembre 2007). Lovaina: Mémosciences, 2008, pp. 21-34; NewmaN, William R. "What have we learned from the recent historiography of alchemy?» Isis, 2011, 102(2), 313321; Newman, William R. y PRINCIPE, Lawrence M. "Alchemy vs. chemistry. The etymological origins of a historiographic mistake». Early Science and Medicine, 1998, 3(1), 32-65.

11. Fontenelle, 1715, op. cit., pp. 75-76. 
NICOLAS LÉMERY (1645-1715) Y SU TEORÍA FÍSICO-QUÍMICA SOBRE DIVERSOS FENÓMENOS...

[destilando, u obrando con rectitud] se hallará la piedra escondidan. Obrar con rectitud, en su vinculación moral mágico-alquímica, implicaba buscar los medios para encontrar una línea recta cuya longitud fuese igual a una línea curva o torcida, como camino de la verdadera voluntad y pilar central hacia lo divino, algo totalmente ajeno al pensamiento lemeriano. Por otro lado, esa piedra escondida ya no es para Lémery, como médico o boticario y menos aún como químico, un objetivo fruto de la fantasía y de la imaginación, una panacea capaz de curar todos los males, sino un componente más de los mixtos, cuya aplicación útil había que investigar. Por mixtos se entendía "las cosas que crecen normalmente, como los minerales, los vegetales, y los animales», y Lémery distingue a su vez en ellos una serie de sustancias según su origen, como los siete metales, los minerales, las piedras y las tierras, para el primer grupo; plantas, gomas, resinas, frutos, hongos, zumos y flores (además del maná, la miel, y otros mixtos imperfectos), para el segundo; y en lo que respecta a los animales, todas sus partes y excrementos ${ }^{12}$.

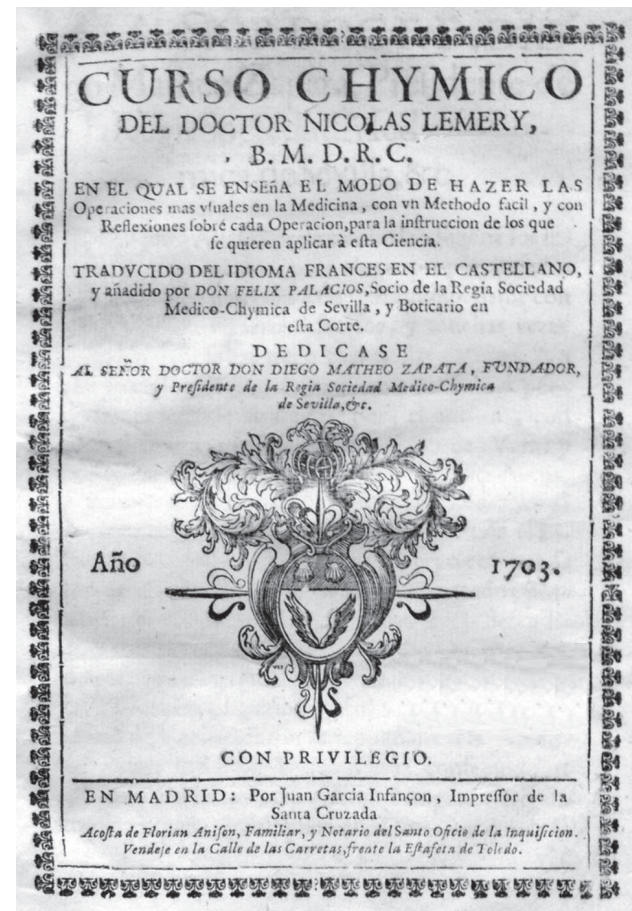

Figura 2. Primera página del Curso Chymico (traducción castellana 1703).

[Biblioteca Nacional, Madrid].

12. LÉMERY, 1703, op. cit., pp. 1-2. 
En cuanto a los principios de la química ${ }^{13}$, y siguiendo esta misma orientación clarificadora, rechazó el principio universal de Paracelso (1493-1541), pero seguía aceptando los cinco clásicos como el Azufre, el Mercurio, la Sal (principios activos), el Agua y la Tierra (principios pasivos); sin embargo, a diferencia de la corriente paracelsista, Lémery los consideraba más bien como una herramienta de trabajo, como constituyentes de una mezcla que pueden separarse mediante la destilación; supuso además que estos principios podrían a su vez ser divisibles, y esperaba que en el futuro pudieran aislarse sus componentes. Defendía en este mismo sentido la idea de que el desarrollo de las técnicas analíticas permitiría a la ciencia aproximarse a las verdades de la naturaleza. Esta idea le sirvió siempre como proyección de futuro, especialmente en sus demostraciones experimentales muy populares que desarrolló públicamente desde 1674 y ante un gran auditorio tanto en el Jardin du Roi, el foco de difusión de la ciencia más importante de la época, como en diferentes laboratorios que tuvo a lo largo de los años en París ${ }^{14}$. A pesar de algunas vicisitudes por problemas de índole religiosa, entre las que hay que destacar su persecución como protestante y un breve exilio en Inglaterra en 1683, estas clases le valieron una gran reputación ${ }^{15}$ por su claridad y su elocuencia, incluso fueron de mayor estima que otras parecidas que se llevaban a cabo, por ejemplo, en Inglaterra y en Holanda ${ }^{16}$, de donde procedían muchos de los estudiosos que asistían a sus demostraciones, en las que se promovía la difusión

13. Ibid., pp. 2-21.

14. Véanse, al respecto, Bouvet, Maurice. "Les laboratoires parisiens de Nicolas Lémery». Revue d'Histoire de la Pharmacie, 1950, 38 année, 126, pp. 24-30; LAISSus y TORLAIs, 1964, op. cit., pp. $287-341$.

15. Por su conversión al catolicismo, esa gran reputación se vio oscurecida en algunos ambientes intelectuales en la segunda mitad del siglo XVIII: entre los enciclopedistas, por ejemplo, su obra como químico, junto con la de otros autores contemporáneos, fue objetada porque según GabrielFrançois Venel estaba llena de errores y carecía de sentido; véase CHYMIE ou CHIMIE. Encyclopédie, ou Dictionnaire raisonné des Sciences, des Art et de Métiers. París: Briasson, David, Le Breton \& Durand, 1753, tomo III, pp. 408-447 (pp. 431-432); fue ignorado, además, por Pierre-Joseph Macquer en su magna obra Dictionnaire de Chimie (París: Lacombe, 1766, 2 tomos), aunque en la segunda edición (París: T. Barrois, 1778, 4 tomos), sí tiene en cuenta sus trabajos (véase, además, la nota 21); por otro lado, Antoine-Laurent de Lavoisier, que había sido indirectamente su alumno a través de su hijo, Louis Lémery, nunca lo cita; véanse GuEDON, Jean-Claude. "Protestantisme et Chimie. Le milieu intellectuel de Nicolas Lémery». Isis, 1974, 65(2), pp. 212-228; Bougard, 1999, op. cit., pp. 6 y 363-364; véase también la nota 55 .

16. En relación con la enseñanza de la química en esa época, véanse, por ejemplo, CleRICUZIO, Antonio. "Teaching chemistry and chemical texbooks in France. From Beguin to Lemery". Science $\mathcal{E}$ Education, 2006, 15(2-4), 335-355; GuERrinI, Anita. "Chemistry teaching at Oxford and Cambridge, circa 1700m. En RatTansi, Piyo y Clericuzio, Antonio (eds.). Alchemy and chemistry in the $16^{\text {th }}$ and $17^{\text {th }}$ centuries (Proceedings Warburg Colloquium 1989). Dordrecht: Kluwer, 1994, pp. 183-199; LAISsus, Yves y TorlaIs, Jean. "Le Jardin du Roi et le Collège Royal dans l'enseignement des sciences au XVIII siècle». En TATON, René (ed.). Enseignement et diffusion des sciences en France au XVIII siècle. París: Hermann, 1964, pp. 259-341; POwERs, John Charles. Inventing chemistry. Herman Boerhaave and the reform of the chemical arts. Chicago (IL): Chicago University Press, 2012, cap. 2. 
NICOLAS LÉMERY (1645-1715) Y SU TEORÍA FÍSICO-QUÍMICA SOBRE DIVERSOS FENÓMENOS...

y el alcance del conocimiento entre toda la gente, muy al contrario que en las prácticas alquímicas.

Por otro lado, Lémery se alejó de la visión animista clásica de la alquimia para explicar la interacción de las sustancias, y aplicó la filosofía mecanicista y la teoría corpuscular. Estas quedaron ya patentes en sus ideas sobre los fenómenos naturales en tanto que dependían de una materia caracterizada por su divisibilidad y afectada por el movimiento, y se reflejaron en su intervención en la controversia sobre ácidos y álcalis desde 1675, con la primera edición de su obra de química ya citada, aunque se suele considerar su ruptura definitiva con la alquimia a partir de la cuarta edición, en 1681. Lémery pensaba que la naturaleza ácida de algunas sustancias se debía a la existencia de puntas en la superficie de estos materiales, mientras que, en los álcalis, las superficies eran porosas ${ }^{17}$; la interacción mecánica entre ambas sustancias durante la agitación, en la que tenía lugar la penetración de las puntas ácidas dentro de los poros alcalinos, era la causante de ciertas operaciones químicas como las fermentaciones y la producción de las sales. Estas ideas se repiten constantemente en casi todas las experiencias que aparecen en su obra, y fueron ampliamente aceptadas durante casi un siglo.

En este contexto de cambio ineluctable de la química, Lémery se acercó también, como muchos otros científicos de la época, a fenómenos de interés general por su naturaleza catastrófica que con el transcurso del tiempo constituirían una parte importante del corpus doctrinal de las Ciencias de la Tierra. Hay que tener en cuenta que la química hizo una relevante contribución al desarrollo de la geología experimental desde sus inicios y a lo largo de los siglos XVII y XVIII ${ }^{18}$, y una parte sustantiva, aunque breve, de los trabajos prácticos de Lémery hay que enmarcarla precisamente en esa gran aportación.

\section{EXPliCaCión FÍsico-Química sobre FenÓmenos QUe CONCIERnEN A LAS CiENCIAS DE LA TIERRA}

Se trata de un pequeño trabajo titulado "Explication physique et chymique des Feux souterrains, des Tremblemens de Terre, des Ouragans, des Eclairs \& du Tonnerre» que Lémery presentó en 1700 en la Académie Royale des Sciences de

17. LÉmerY, 1703, op. cit., pp. 16-17; véanse, además, LAFOnT, Olivier. "Nicolas Lémery et l'acidité». Revue d'Histoire de la Pharmacie, 2002, 90 année, 333, pp. 53-62; LeICESTER, Henry Marshall y KuICKSTEIN, Herbert Sidney. A source book in chemistry, 1400-1900. Nueva York: MacGraw Hill, 1952, pp. 53-54.

18. Una excelente revisión sobre esta contribución se puede ver en NEwCOMB, Sally. The world in a crucible. Laboratory practice and geological theory at the beginning of geology. Geological Society of America Special Paper, 2009, vol. 449, 204 pp.; véanse, además, LAUDAN, Rachel. From mineralogy to geology. The foundations of a science. Chicago (IL): Chicago University Press, 1987 (ed. 1993), cap. 2; Sigurdsson, Haraldur. Melting the earth. The history of ideas on volcanic eruptions. Oxford-New York: Oxford University Press, 1999, cap. 12. 
París ${ }^{19}$. En esta memoria, utilizando diversos conceptos desarrollados en su Curso, proporcionaba una explicación físico-química de una serie de fenómenos que tienen que ver actualmente con las Ciencias de la Tierra, como son los terremotos y los volcanes o fuegos subterráneos, para la geología, y los huracanes, los rayos y los truenos, para la meteorología como rama de la geofísica. Las experiencias de Lémery en este sentido están consideradas como uno de los trabajos pioneros de la ciencia geológica experimental.

DE S S I E N C E S. IZT gles, en ayant fuffifamment parlé dans le $\mathrm{Mc}$ moire du 30. Janvier dernier. D'ailleurs il n'y a pas moyen de s'éteridre ici davantage.

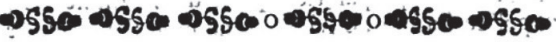

E X P L I ATION

Pbyjague of Chymique dies Feux fouterrains, des Tremblemens de terre, des Ouragans, des Eclairs of dis Toninerre.

Par M. L E M E R Y.

* M $\mathrm{O}_{\mathrm{N}}$ deffein eft de donner par le moyen d'une operation de Chymie, une idée fenlible de ce qui fe paffe dans les nues lorfqu'ellès s"ouvrent en temps de tempête, pour produire les Eclairs \& le Tonnerre: mais avant que de faire voir cette operation, il eft à propos de parler de la matiere qui caufe des effets li violens, $\&$ d'examiner fá hature \& fon origine.

On ne peut pas raifonnablement douter que la matiefre de l'Eclair \& du Tonnerre, ne foịt un foulfre enflammé \& élaucé av̀ec beaucoup de rapidité. Nous ne connoiffous rien d'inflammable ni de plús en mouvement que le foulfre; \& Todeur de foulfre qué le Tonnerre laiffe dans tous les lieux où il a paffé, prouve affez fa nature : it eft donc queftion piéfentement de trouver l'origine de ce foulfre; il n'eft pas vrai-fembläble qứil fe foit formé dans les nues, il faut. qu'il y ait été porté en vapeur.

Ir me parốt que l'origine de la matiere qui-

*-21. Avril. J700:

Figura 3. Primera página de la explicación físico-química sobre fenómenos geológicos (Lémery, 1700/1706, p. 131). [Bibliothèque Nationale de France, Paris].

19. Véase, más adelante, Sobre la presente traducción. 
Estos experimentos fueron conocidos genéricamente como vulcán o volcán de Lémery, y como ya se ha comentado, a sus demostraciones públicas asistían curiosos de toda Europa. En esta operación, que consistía en una fermentación húmeda con limaduras de hierro y azufre pulverizado (flor de azufre), se liberaba energía en forma de calor, y, dependiendo de las condiciones experimentales, se producía un incendio que podía ir acompañado de una fuerte detonación. La explicación físico-química que daba Lémery estaba basada en su modelo corpuscular y mecanicista ácido-base, en el cual las puntas ácidas del azufre penetraban en las superficies porosas del hierro, cuya fricción generaba todas esas manifestaciones energéticas. Esta era la causa tanto para los incendios subterráneos y los terremotos, que se originaban bajo tierra, como para los huracanes, los rayos y el trueno que afectaban a la atmósfera, proporcionando, según la percepción de la época, grandes esclarecimientos en el campo de la Física ${ }^{20}$.

La clave del porqué de estas experiencias, y de su gran aceptación ${ }^{21}$ en general durante las siguientes décadas, reside en la visión actualista que ya existía en la comunidad científica y que, además, llevaba consolidada en el pensamiento corriente desde hacía siglos; en breves palabras podemos resumirla como sigue: simular lo que ocurre en la naturaleza para obtener los mismos efectos a partir de las mismas causas. Esto quedó reflejado en la presentación previa que hizo Fontenelle de esta memoria de Lémery: «El mejor medio de explicar la Naturaleza, si pudiera hacerse regularmente, sería la de imitarla, y hacer, por así decirlo, representaciones, produciendo los mismos efectos con las mismas causas que son conocidas, y que se habrían puesto en acción. Se vería de esta forma que los fenómenos naturales tendrían las mismas causas que los artificiales, o al menos causas muy parecidas ${ }^{22}$.

En su modelo, Lémery tuvo en consideración una creencia muy antigua para explicar estos fenómenos partiendo asimismo de una idea general: la existencia de un planeta horadado por multitud de canales, pasajes, cuevas, rendijas, y otros tipos de conductos, por los que circulaba el fuego, el agua o el aire a diferentes temperaturas; la fuerza de estas exhalaciones se traducía en la superficie terrestre en terremotos o erupciones volcánicas, cuando no se manifestaba con la misma

20. Journal de Sçavans, 1703, XXIX (Du Lundy 23. Juillet), p. 452.

21. Una vez más, los enciclopedistas, en este caso Louis de Jaucourt, ignoraron el nombre de Lémery, aunque no su explicación sobre la causa de los fuegos subterráneos; véase volcANs. En Encyclopédie, ou Dictionnaire raisonné des Sciences, des Art et de Métiers. Neufchastel: Samuel Faulche, 1765, tomo XVII, pp. 443-446. En relación con los temblores de tierra, sí se cita la explicación de Lémery, pero para criticarla; véase TREMBLEMENS DE TERRE. En Encyclopédie, ou Dictionnaire raisonné des Sciences, des Art et de Métiers. Neufchastel: Samuel Faulche, 1765, tomo XVI, pp. $580-583$ (p. 581); véase, por otro lado, la nota 55.

22. Fontenelle, Bernard Le Bovier de. "Sur les feux souterrains, les tremblemens de terre, le tonnerre, \&c. expliquez chimiquement». Histoire de l'Académie Royale des Sciences, Année M. DCC, avec les Mémoires de Mathématiques et de Physique pour la même année. Ámsterdam: G. Kuyper, 1700 (publicado en 1706), pp. 65-66. 
NICOLAS LÉMERY (1645-1715) Y SU TEORÍA FÍSICO-QUÍMICA SOBRE DIVERSOS FENÓMENOS...

procedencia pero en la atmósfera como huracanes, rayos o truenos ${ }^{23}$. Esta visión de semejante mundo subterráneo aparece en ya en los clásicos greco-latinos, con Aristóteles (384-322 a. C.) ${ }^{24}$, Séneca ( 4 a. C.-64 d. C.) ${ }^{25}$, o Plinio el Viejo (23-79 d. C. $)^{26}$, como exponentes de la misma. Alcanzó su máxima expresión en 1665, en la obra del jesuita alemán Athanasius Kircher (1601/2-1680), que lleva precisamente ese título, Mundus Subterraneus, donde manifiesta también estas ideas clásicas sobre el interior de la Tierra, y en la que describe todo un geocosmos de corte organicista con un fuerte componente teológico ${ }^{27}$.

Lémery pensaba que estas cavidades subterráneas eran las vías de escape de la energía mecánica o térmica, cuyo origen concuerda con algunas concepciones renovadoras de la química, dentro de la tradición modernizadora de la época, como son las fermentaciones minerales como fuentes de calor. Estas ideas, en las que el azufre era el elemento fundamental junto con la nitro o salpetre (nitrato de potasio) o el hierro, habían sido tratadas también por Robert Boyle en la segunda mitad del siglo XVII ${ }^{28}$, y que recogerían asimismo otros autores contemporáneos como Martin Lister (1639-1712) ${ }^{29}$,

23. CAPEL, Horacio. "Organicismo, fuego interior y terremotos en la ciencia española del siglo XVIII». GeoCrítica, 1980, 27-28, pp. 5-94; GuIDOBONI, Emanuela. "Earthquakes, theories from antiquity to 1600». En GooD, Gregory Allan (ed.). Sciences of the Earth: An encyclopedia of events, people, and phenomena. New York: Garland, 1998a, vol. I, pp. 197-205; OESER, Ebhard. «Historical earthquake theories from Aristotle to Kant". Abhandlungen der Geologischen Bundesanstalt, 1992, 48, pp. 11-31; Oldroyd, David Roger. Thinking about the Earth: A history of ideas in Geology. Londres: Athlone, 1996, cap. 2; QUENET, Grégory. Les tremblements de terre aux XVIIe et XVIIIe siècles: La naissance d'un risque. Seysell: Champ Vallon, 2005, pp. 216-218; SHuTE, Michael N. "Ancient imagination and seismic disruption». Yale Review, 1979, 69, pp. 55-71; SiguRdSSON, 1999, op. cit., caps. 4-5.

24. ARIstóteles. Los Meteorológicos. Madrid: Alianza (trad. castellana 1996), Libro II, 365a-367b; ARistóteles (Pseudo-). De Mundo. Oxford: Oxford University Press (trad. inglesa 1914), 395a-b.

25. SÉNECA, L.A. Naturales Quaestiones. Madrid: CSIC (ed. bilingüe, trad. castellana 1979), 62 d.C., tomo I, Libro III.16.4 y 26.3; tomo II, Libro VI.6-24.

26. Plinio EL Viejo Historia Natural. Madrid: Gredos (trad. castellana 1995), c. 77 d.C., vol. I, Libro II, 79-80.

27. KirCHER, Athanasius. Mundus subterraneus. Amsterdam: J. Janssonius, 1665, tomo I, Libro IV. [Trad. inglesa (selección de textos): The Volcano's, or burning and fire-vomiting mountains famous in the world. Londres: John Allen, 1669, 64 pp.]; véanse, además, SEQUEIROS, Leandro. «El Geocosmos teológico de Athanasius Kircher (1601-1680)». Proyección, 2000, XLVII(199), pp. 281-300; SEQUEIROS, Leandro. "El Geocosmos de Athanasius Kircher. Una imagen organicista del mundo en las Ciencias de la Naturaleza en el siglo XVII". Llull, Revista de la Sociedad Española de Historia de las Ciencias y de las Técnicas, 2001, 24, pp. 755-807; SIERRA VALENTí, Eduardo. «El Geocosmos de Kircher. Una cosmovisión científica del siglo XVII». GeoCrítica, 1981, 33/34, pp. 1-81.

28. Boyle, Robert. El químico escéptico. Barcelona: Crítica (trad. castellana 2012), 1661, parte I, pp. 59-89.

29. LISTER, Martin. "Of the nature of earthquakes; more particularly of the origin of matter of them, from the pyrites alone». Philosophical Transactions of the Royal Society of London, 1684, 14(157), pp. 512-515 (reproducido en BEvIS, John (ed.). The history and philosophy of earthquakes, from the remotest to the present time. Londres: J. Nourse, 1757, pp. 59-67). 
y Robert Hooke $(1635-1703)^{30}$, o, ya a principios del siglo XVIII, Isaac Newton $(1642-1727)^{31}$. El trabajo de Lémery tuvo una enorme difusión en Europa, y fue además de gran repercusión especialmente después de dos terremotos que conmocionaron al mundo a mediados del siglo XVIII: el de Perú, que afectó a Callao y Lima el 28 de octubre de 1746 (zonas ya destruidas por una actividad sísmica anterior, el 20 de octubre de 1687), y, sobre todo, el de Lisboa, que asoló la capital portuguesa el 1 de noviembre de 1755 y se sintió en buena parte de Europa occidental y norte de África. De la explicación lemeriana se hicieron eco muchos de los pensadores contemporáneos ${ }^{32}$, aunque también fue ignorada ${ }^{33}$; pero sin duda donde tuvo más repercusión fue en las ideas de Immanuel Kant (1724-1804) sobre el origen de los temblores de tierra ${ }^{34}$, e influyó, por otro lado, hasta en su forma de entender la propia filosofía ${ }^{35}$.

30. HoOKe, Robert. "Lectures and discourses of earthquakes, and subterraneous eruptions". En Waller, Richard (ed.). The posthumous works of Robert Hooke. Londres: Smith \& Walford (1705), 1668-1700, pp. 277-450 (Discourse No 26/1699, pp. 425-426); reproducido en Drake, Ellen Tan. Restless genius. Robert Hooke and his earthly thoughts. New York: Oxford University Press, 1996, pp. 159-365 (pp. 358-363)].

31. Newton, Isaac. Óptica. Madrid: Alfaguara (trad. castellana 1977), 1704, Libro III, parte I, pp. 325-328.

32. BREIDERT, Wolfgang (ed.). Die Erschütterung der vollkommenen Welt. Die Wirkung des Erdbebens von Lissabon im Spiegel europäischer Zeitgenossen. Darmstadt: Wissenschaftliche Buchgesellschaft, 1994 , VI+234 pp. Asimismo, P.-J. Macquer, que había ignorado a Lémery en 1766 en su Dictionnaire de Chimie (véase nota 15), en la segunda edición de esta obra considera apropiada su explicación sobre las fermentación de las piritas como causa de los fuegos subterráneos y los terremotos; véase MACQUER, 1778, op. cit., tomo II, p. 309.

33. OwEn, William. The general theory and phonomena of earthquakes and volcanoes. London: W. Owen Bookseller, 1756, 62 pp.

34. KANT, Immanuel. "Von den Ursachen der Erderschütterungen bei der Gelegenheit des Unglücks, welches die westlichen Länder von Europa gegen das Ende des vorigen Jahres getroffen hat». En Kant's Werke. Berlín: G. Reimer (1910), 1756a, tomo I (Vorkritische Schriften I, 1747-1756), pp. 417-427; KANT, Immanuel. "Geschichte und Naturbeschreibung der merkwürdigsten Vorfälle des Erdbebens, welches an dem Ende des 1755sten Jahres einen großen Theil der Erde erschüttert hat». En Kant's Werke. Berlin: G. Reimer (1910), 1756b, tomo I (Vorkritische Schriften I, 1747-1756), pp. 429-461; KANT, Immanuel. «Fortgesetzte Betrachtung der seit einiger Zeit wahrgenommenen Erderschütterungen». En Kant's Werke. Berlín: G. Reimer (1910), 1756c, tomo I (Vorkritische Schriften I, 1747-1756), pp. 463-472; véanse, además, AMADOR, Filomena. "The causes of 1755 Lisbon earthquakes on Kant". Actas VIII Congreso de la Sociedad Española de Historia de las Ciencias y de las Técnicas (Logroño/2002), 2004b, vol. 2, pp. 485-495; Guidoboni, Emanuela. "Earthquakes, theories from 1600 to 1800». En GoOD, Gregory Allan (ed.). Sciences of the Earth: An encyclopedia of events, people, and phenomena. Nueva York: Garland, 1998b, vol. I, pp. 205-214; HernáNDEZ MARCOS, Maximiliano. "Un texto de Immanuel Kant sobre las causas de los terremotos (1756)». Cuadernos Dieciochistas, 2005, 6, pp. 215-224; KozÁK, Jan y ČERMÁK, Vladimir. Illustrated history of natural disasters. Nueva York: Springer, 2010, pp. 131-142; REINHARDT, Oscar y OLDROYD, David Roger. "Kant's theory of earthquakes and volcanic action". Annals of Science, 1983, 40(3), pp. 247-272.

35. LARSEN, Svend Erik. "The Lisbon earthquake and the scientific turn in Kant's philosophy". European Review, 2006, 14(3), pp. 359-367. 
NICOLAS LÉMERY (1645-1715) Y SU TEORÍA FÍSICO-QUÍMICA SOBRE DIVERSOS FENÓMENOS...

\section{CONSIDERACiOnes Finales}

De todas las ideas de Lémery, casi ninguna ha superado, como se suele decir, la prueba del tiempo. Su modelo ácido-base, y las relaciones físico-químicas de las fermentaciones minerales con los fenómenos geológicos expuestos, aunque se mantuvieron casi un siglo en vigor como explicaciones válidas dentro del contexto del desarrollo científico de la época, resultaron ser incorrectas. En los textos tanto de química como de geología, salvo alguna rara excepción, se ignora la existencia de este eminente científico y de su obra. Solo los libros de historia de la química y, con mayor brevedad, los de historia de la geología, tratan sobre él. De su "volcán" se recogen breves definiciones en algunas enciclopedias ${ }^{36}$, y en el ámbito de la enseñanza, por otro lado, queda relegado, y solo ocasionalmente, a su discusión ${ }^{37}$.

Sin embargo, consideramos imprescindible destacar algunos aspectos de las ideas lemerianas para mostrar, a través de su figura, lo que ha sido el funcionamiento de la ciencia durante esa etapa trascendental de innovación y transformación.

En primer lugar, su ruptura con la alquimia y el esoterismo contribuyó a abrir el camino hacia la revolución científica liderada, entre otros autores, por AntoineLaurent de Lavoisier (1743-1794) en las últimas décadas del siglo XVIII ${ }^{38}$. Trasmitió su pasión por la química con sus demostraciones experimentales, la liberó de su secretismo hermético, y la convirtió en una ciencia popular entre las clases cultas de toda Europa. Sus explicaciones sobre los terremotos y los volcanes contribuyeron a hacer de ellos fenómenos naturales, independientes de cuestiones morales derivadas de la providencia divina. En cierto sentido existe una relación entre los procesos químicos, volcánicos y determinados seísmos, pero esa dependencia no es tal y como la entendía Lémery. Por este motivo, la modelización o simulación práctica de su volcán podría ayudar asimismo a comprender algunos principios epistemológicos fundamentales como, por ejemplo, el hecho de que una idea, una hipótesis o una teoría no es necesariamente correcta aunque tenga apoyos observacionales y/o experimentales, y que, al mismo tiempo, un experimento no es más que es una herramienta en los procesos de falsación, que simplemente apoya o refuta aquello que se quiere falsar, pero no demuestra nada (en realidad, solo se demuestran los teoremas matemáticos). Finalmente, y esta visión lemeriana se fue confirmando a lo largo del tiempo y ha perdurado hasta el presente, su

36. Enciclopedia Universal Ilustrada Europeo-Americana. Madrid: Espasa-Calpe, 1968, tomo LXIX, p. 956; Gran Enciclopedia Larousse, Barcelona: Planeta, 1972, tomo 10, p. 862.

37. Amador, Filomena. "Los 'volcanes' de Nicholas Lemery (1645-1715)». Enseñanza de las Ciencias de la Tierra, 2004a, 12(3), pp. 253-259.

38. Este liderazgo por parte de Lavoisier ha sido cuestionado por algunos estudios historiográficos modernos; una excelente síntesis al respecto puede verse, por ejemplo, en BERTOMEU SÁNCEZ, José Ramón. "La revolución química: entre la historia y la memoria». DYNAMIS, Acta Hispanica ad Medicinae Scientiarumque Historiam Illustrandam, 2006, 26, 307-322; BERTOMEU SÁNCHEz y GARCíA Belmar, 2006, op. cit. 
confianza en que el desarrollo de las técnicas de análisis acercaría la ciencia a las verdades del mundo natural es una buena muestra de que muchas veces lo que sobreviven a lo largo del tiempo no son los conceptos supuestamente establecidos, aparentemente bien definidos y coherentes, sino las metodologías, sin las cuales sería imposible abrir nuevas vías hacia el conocimiento de la verdad.

Todas estas consideraciones son más que suficientes para rendir homenaje a Nicolas Lémery en conmemoración del tercer centenario de su fallecimiento, y presentar como contribución a ello la traducción castellana de sus disquisiciones sobre fenómenos que con posterioridad serían objeto de las Ciencias de la Tierra (véase el Apéndice).

\section{SOBRE LA PRESENTE TRADUCCIÓN}

Este trabajo de Lémery fue presentado en la asamblea de la Académie Royale des Sciences de París celebrada el 21 de abril de 1700, aunque se publicó tres años más tarde en la obra anual de historia y memorias de dicha institución ${ }^{39}$; de esta publicación existen varias reediciones tanto en Francia como en Holanda ${ }^{40}$. Después del fallecimiento de su autor, y dado su gran predicamento, a mediados del siglo XVIII esta memoria tuvo dos traducciones, una al alemán en 1748 por Wolf Balthasar Adolph von Steinwehr ${ }^{41}$, y otra al inglés que fue incluida en el tratado sobre historia y filosofía de los terremotos que editó John Bevis en $1757^{42}$.

La influencia y relevancia de este trabajo durante más de un siglo en el ámbito de la geología experimental es una de las razones que nos ha impulsado a su traducción castellana. Hemos utilizado para la presente traducción una copia del original de la edición holandesa de 1706 que se conserva en la Bibliothèque Nationale de Francia (París). Como en otros trabajos de esta misma índole que hemos llevado a cabo con anterioridad, se han seguido las normas básicas que consideramos constituyen la regla de oro de cualquier traducción y que se deben al filólogo español Valentín García Yebra (1917-2010), a saber: Decir

39. LÉMERY, Nicolas. "Explication physique et chymique des Feux souterrains, des Tremblemens de Terre, des Ouragans, des Eclairs \& du Tonnerre». Histoire de l'Académie Royale des Sciences, Année M. DCC, avec les Mémoires de Mathématiques et de Physique pour la même année. Paris: Jean Boudot, 1700 (publicado en 1703), pp. 101-110.

40. Cronológicamente (el rango de páginas se corresponde con el trabajo de Lémery), Ámsterdam: Gerard Kuyper, 1706 (pp. 131-142); París: Charles Estienne Hochereau, 1719 (pp. 101-110); Ámsterdam: Pierre Mortier, 1734 (pp. 140-152); Paris: Gabriel Martin, Jean-Baptiste Coignard \& Hyppolite-Louis Guerin, 1761 (pp. 101-110).

41. "Physische und chymische Erklärung der unterirdischen Feuer, der Erdbeben, Stürme, des Blitzes und Donners". Der Königlich Akademie der Wissenschaften in Paris physische Abhandlungen, Erster Theil, 1748, pp. 417-427.

42. "A physico-chemical explanation of subterraneous Fires, Earthquakes, \&c. by M. LÉMERY of the Royal Academy of Sciences at Paris». En BEvIS, 1757, op. cit., 1757, pp. 183-192. 
NICOLAS LÉMERY (1645-1715) Y SU TEORÍA FÍSICO-QUÍMICA SOBRE DIVERSOS FENÓMENOS...

todo lo que dice el original, no decir nada que el original no diga, y decirlo con la corrección que permite, en este caso, el castellano ${ }^{43}$. Se ha mantenido la paginación original entre corchetes, cursiva y negrita, indicando el inicio de cada página. También se ha añadido un conjunto de notas a pie de página con aclaraciones que permiten una mejor comprensión del texto, en las que se identifican todos los términos químico-alquímicos obsoletos que se utilizaban en esa época ${ }^{44}$.

\title{
5. APÉNDICE
}

$[131]^{45}$

EXPlicación Física y Química de los Fuegos SubTerRáneOS, los Temblores de Tierra, los Huracanes, los Rayos y el TruenO ${ }^{46}$

\author{
Por M. Lémery \\ Traducción castellana y notas de \\ Cándido Manuel García Cruz
}

ES mi deseo proporcionar, mediante una operación de la Química, una idea apreciable de lo que pasa en las nubes, cuando se rompen en tiempos de tormenta, para producir los rayos y los truenos: pero antes de mostrar esta operación, tengo el propósito de hablar de la materia que causa los efectos tan violentos, y examinar su naturaleza y su origen.

No se puede dudar de una manera razonable que la materia que ocasiona el rayo y el trueno no sea un azufre inflamado y desprendido con gran rapidez. No conocemos otra cosa inflamable, o que se agite, que el azufre, y el olor a azufre que el trueno deja allí por donde pasa, es prueba suficiente de su naturaleza: la cuestión es, pues, preferentemente encontrar ahora el origen de este azufre; no es cierto que se haya formado en las nubes, ha debido llegar hasta allí en forma de vapor.

43. García Yebra, Valentín. Prólogo. En Metafísica de Aristóteles. Madrid: Gredos (ed. trilingüe), 1970 , p. XXVII.

44. Para la equivalencia actual de estos términos se ha consultado preferentemente EKLUND, John. The incompleat chymist: Being an essay on the Eighteenth-Century chemist in his laboratory, with a dictionary of obsolete chemical terms of the period. Washington: Smithsonian Institution Press, 1975, 49 pp.; también han sido de utilidad GuYTON DE MORveau, Louis B.; LAVOISIER, Antoine L.; Berthollet, Claude L. y Fourcroy, Antoine F. de. Método de la nueva nomenclatura química. Madrid: Antonio de Sancha, 1788 (de la $1^{\text {a }}$ ed. francesa 1787), pp. 70-176; Crosland, Maurice P. Historical studies in the language of chemistry. Londres: Heinemann, 1962, XVII+406 pp.; TERREROS Y PANDO, Esteban de. Diccionario castellano con las voces de ciencias y artes. Madrid: Viuda de Ibarra, 1786-1793, tomos 1-3 (ed. facsímile en Madrid: Arco Libros, 1987).

45. Los números entre corchetes indican la paginación original (inicio de página).

46. LÉMERY, Nicolas. "Explication physique et chymique des Feux souterrains, des Tremblemens de Terre, des Ouragans, des Eclairs \& du Tonnerre». Histoire de l'Académie Royale des Sciences, Année M. DCC, avec les Mémoires de Mathématiques et de Physique pour la même année. Amsterdam: Gerard Kuyper, 1700 (publicado en 1706), pp. 131-142. 
Me parece que el origen de la materia que [132] forma el trueno es la misma que la de los temblores de tierra, los huracanes, y los fuegos subterráneos; ya he explicado la causa de estas grandes alteraciones en mi Libro de Química ${ }^{47}$ con ocasión de una preparación particular sobre el hierro, llamada Azafrán de Marte ${ }^{48}$, que publiqué hace muchos años; y como mi explicación se ha encontrado correcta, y que incluso después de la última edición ${ }^{49}$ de este libro he hecho muchas otras experiencias que sirven para confirmar lo que había avanzado, solicito a los presentes $^{50}$ me consientan informar brevemente de estas y de otras experiencias, y me permitan vincular lo más sucintamente que sea posible lo principal de la explicación que he dado, con la que tendría el honor de expresar hoy aquí. Esta relación servirá para hacer más comprensible mi discurso, e informará a los que aún no han leído mi libro de lo que contiene al respecto; he aquí, pues, los primeros experimentos.

Se hace una mezcla de partes iguales de limadura de hierro y azufre pulverizado; se reduce la mezcla en una pasta con agua y se deja en digestión en ausencia de fuego ${ }^{51}$ durante dos o tres horas. Se produce una fermentación ${ }^{52}$ y una hinchazón con desprendimiento de abundante calor; esta fermentación rompe la masa en varios lugares, y produce grietas por donde salen vapores simplemente calientes, aun cuando no quede más que una cantidad ínfima del material, pero que se inflaman cuando la materia de donde proceden forma una masa considerable como de treinta o cuarenta libras ${ }^{53}$.

47. Se refiere a LÉMERY, 1675, op. cit., pp. 111-118. En la versión castellana, LÉmERY, 1703, op. cit., pp. 104-114.

48. Azafrán de Marte: óxido de hierro(III) $\left(\mathrm{Fe}_{2} \mathrm{O}_{3}\right)$, conocido también como azafrán de hierro o herrumbre; a veces se le llamaba así también al óxido ferroso-férrico $\left(\mathrm{Fe}_{2} \mathrm{O}_{4} \cdot \mathrm{xH}_{2} \mathrm{O}\right)$, o al sulfuro de hierro(III) $\left(\mathrm{Fe}_{2} \mathrm{~S}_{3}\right)$. Sobre las equivalencias modernas de los términos obsoletos, véase nota 44.

49. La última edición citada aquí por Lémery de su libro de química fue la 9ª y apareció en 1697; a partir de esta se hizo precisamente la traducción castellana (1703).

50. Se refiere a los asistentes a la sesión pública de la Académie Royale de Sciences de París, donde Lémery presentó esta memoria el 21 de abril de 1700.

51. Lémery hace referencia aquí en realidad a un calor muy débil, sin aplicación de fuego directo, puesto que la digestión de una sustancia consistía en someterla a la acción del calor para ablandarla, pero sin llegar a hervir (LÉMERY, 1703, op. cit., p. 34). En cualquier caso, y aunque en este trabajo no se especifica, el fuego era un medio o instrumento para llevar a cabo un análisis químico, y se distinguían diferentes grados de fuego y calor según las necesidades de cada experiencia práctica, cada uno de ellos con su propia denominación (Ibid., pp. 31-33). Estas ideas sobre el calor y el fuego se encuentran también en Aristóteles, quien en su obra sobre la generación y la corrupción de la materia sostenía en concreto que «el fuego es un exceso de calor»; ARISTÓTELES. Acerca de la generación y la corrupción. Tratados breves de historia natural. Madrid: Gredos (trad. castellana 1987), Libro II, cap. 3, 330b. 25 .

52. Por fermentación se entendía la putrefacción o descomposición natural de una sustancia.

53. La libra francesa, como unidad de peso, tenía la siguiente equivalencia: 1 libra (livre) $=16$ onzas $($ ounce $) ; 1$ onza $=8$ gruesos $($ gros $) ; 1$ grueso $=72$ granos (grain) (véanse las notas 64 y 75). Su valor variaba, según las regiones, entre 380-552 g. A propuesta de Lavoisier, tras la Revolución Francesa, en 1795, se unificó con una equivalencia de 489,503 g. 
La fermentación acompañada de calor, y al mismo tiempo de fuego, que llega en esta operación, pro-[133]-cede de la penetración y del rozamiento violento de las puntas ácidas ${ }^{54}$ del azufre contra las partículas de hierro.

Creo que esta experiencia es capaz de explicar por sí sola de qué forma se producen en las entrañas de la tierra las fermentaciones, los movimientos y los incendios $^{55}$, tal y como llegan al Monte Vesubio, al Monte Etna, y a muchos otros lugares; porque si se encuentran el hierro y el azufre, que se unen y se penetran mutuamente, debe seguir una fermentación violenta que produce fuego como en nuestra operación. Es fácil de probar que en las montañas de las que he hablado, hay azufre y hierro; porque después de que las llamas se han apagado se encuentra mucho azufre en la superficie de la tierra; y en las grietas por donde ha pasado el fuego se descubren materiales similares a los que se separan del hierro en las forjas.

He aquí las segundas experiencias que he hecho después de la última edición de mi Libro, que apoyarán las primeras y mi razonamiento.

Puse la misma mezcla de limadura de hierro y azufre en diferentes cantidades en ollas altas y estrechas, de suerte que el material estuvo más comprimido que en terrinas; se produjeron también fermentaciones e incendios muy fuertes, y el material se levantó con una cierta violencia, salpicando parcialmente alrededor de las ollas.

En verano, puse cincuenta libras de la misma mezcla en una olla grande, y la coloqué en un hueco que había enterrado en el campo, lo cubrí con un paño y a continuación con tierra a una altura aproximadamente de un $\operatorname{pie}^{56}$, y después [134] de ocho o nueve horas observé que la tierra se hinchó, se calentó y se agrieto; a continuación expulsó vapores sulfurosos y calientes, y luego algunas llamas que agrandaron las aberturas, y que propagaron alrededor del lugar un polvo amarillo y negro: la tierra permaneció mucho tiempo caliente; lo levanté después de que su hubiese enfriado, y no encontré en la olla más que un polvo negro y pesado; se trata de la limadura de hierro despojada de una parte de su azufre; se habría podido meter más tierra en la olla, pero temía que el material no se inflamara por

54. Estas ideas de Lémery están basadas en la teoría corpuscular de la materia y en el mecanicismo (véase la Introducción).

55. Estos experimentos fueron ampliamente conocidos bajo la denominación de «Volcán de Lémery». Sin embargo, aunque esta explicación fue ignorada u objetada durante el siglo XVIII por algunos autores (véase la nota 15), también fue reconocida entre otros, por Buffon, quien, aunque no cita a Lémery, hace referencia implícita a él como «un Físico» (physicien, en el original, término que también se utilizaba en esa época para los médicos); véase Buffon, Georges Louis Leclerc, Conde de. "Preuves de la Théorie de la Terre». En Histoire Naturelle, générale et particulière. París: Imprimerie Royal, 1744 (ed. 1749), tomo I, Article XVI (Des Volcans \& des Tremblemens de Terre), pp. $502-535$ (pp. 503-504). [Existen diferentes ediciones castellanas de esta obra; véase, por ejemplo: "Pruebas de la Teórica de la Tierra». En Historia Natural, general y particular. Madrid: Viuda de Ibarra (trad. castellana 1786), tomo II, Artículo XVI (De los Volcanes, y los Terremotos), pp. 260-348 (pp. 261-262)].

56. El pie (pié, pied), en referencia al sistema parisiense, equivalía a $32,48 \mathrm{~cm}$. 
NICOLAS LÉMERY (1645-1715) Y SU TEORÍA FÍSICO-QUÍMICA SOBRE DIVERSOS FENÓMENOS...

falta de aire. Esta operación resulta mejor en verano que en invierno, debido a que el calor del sol provoca una gran agitación de las partículas insensibles del hierro y del azufre.

No es necesario, pues, investigar en otro lado lo que puede agitar el azufre de las minas e inflamarlo; su unión con el hierro causará perfectamente este efecto, el mismo que ha producido en nuestras operaciones.

Pero aquí se presenta una dificultad; y es que estas grandes fermentaciones y estos incendios subterráneos no pueden haberse producido sin aire; mas no se comprende bien por dónde habría podido pasar el aire hasta esa gran profundidad de la tierra.

Se responde a esta objeción que existen en la tierra muchas fisuras y conductos que no vemos, y principalmente en los países cálidos, donde por lo general ocurren estos movimientos subterráneos; porque el enorme calor del sol calienta y calcina, por así decirlo, la tierra en numerosos lugares, y produce grietas profundas por donde se puede introducir el aire ${ }^{57}$.

[135] Los temblores de tierra son causados aparentemente por un vapor que se habría producido en la fermentación violenta del hierro y del azufre, se convierte en un viento sulfuroso, que pasa y se mueve por donde puede, levantando y haciendo temblar la tierra bajo la que pasa. Si este viento sulfuroso se encuentra siempre encerrado sin poder penetrar por cualquier salida para escapar, los temblores de tierra pueden durar mucho tiempo, hasta que deje de moverse; pero si encuentra algunas aberturas para salir, se apresura con gran impetuosidad, y es lo que se denomina huracán, la tierra se abre y se producen simas, se arrancan árboles, se caen las casas; y los hombres mismos no estarían al abrigo de su furia, si no tomaran la precaución de echarse rápidamente boca abajo en la tierra, no solo para impedir ser levantados, sino para evitar respirar este viento sulfuroso y caliente que los asfixiaría.

Los fuegos subterráneos proceden de la misma exhalación sulfurosa; la diferencia de los efectos que produce puede provenir de numerosas causas; que la materia ha sido más abundante, y en consecuencia la fermentación ha sido más fuerte; que se ha introducido más aire; que este ha encontrado fisuras o grietas en la tierra y dispuestas para dejar pasar las llamas: estas llamas se elevan impetuosamente, cada día más grandes, y dan lugar a que toda la materia del fondo de la tierra se inflame y empuje los fuegos tan abundantes, y que sus cenizas cubran e inunden algunas veces los pueblos cercanos.

[136] Los fuegos fatuos y los que aparecen sobre ciertas aguas en los países cálidos, tienen su origen aparentemente en la misma causa; como el vapor sulfuroso se ha debilitado, y su gran agitación se ha reducido mientras se filtra a través de las tierras y pasa por las aguas, tan solo se eleva una ligera llama, espiritosa,

57. Recuérdese lo dicho en la Introducción sobre la creencia en la existencia de estas fisuras y grietas en la Tierra. 
NICOLAS LÉMERY (1645-1715) Y SU TEORÍA FÍSICO-QUÍMICA SOBRE DIVERSOS FENÓMENOS...

errante, y que no se mantiene sino por una mayor cantidad de materia para que sea duradera.

Parece que las aguas minerales termales, como las de Bourbon, de Vichi, de Baraluc, de Aix, han obtenido su calor de los fuegos subterráneos o de las tierras sulfurosas y calientes por donde han pasado ${ }^{58}$ : porque cuando estas aguas están en reposo, se separa parte del azufre a los lados de las cubetas.

Puede ocurrir también que ciertas aguas minerales hayan tenido su origen en el calor de una cal ${ }^{59}$ natural que encontraron en su camino en las entrañas de la tierra; pero esta cal no es más que una roca calcinada ${ }^{60}$ por los fuegos subterráneos.

Las columnas de agua ${ }^{61}$ que se elevan a veces sobre el mar, y que son para los marinos los siniestros presagios de un pronto naufragio, proceden aparentemente de estos vientos sulfurosos, empujados con rapidez desde las tierras bajo el mar, tras las fermentaciones parecidas a las citadas.

Los vientos sulfurosos que constituyen los huracanes, se elevan con tanta violencia al escapar de debajo de la tierra, que una parte llega hasta las nubes; esto es lo que forma y causa el trueno: porque este viento que contiene un azufre agitado se inflama en las nubes, al ser golpeado y comprimido fuerte-[137]-mente adquiere una agitación mayor por lo que se inflama y forma el rayo que surca la nube, lanzándolo con una enorme velocidad: es esta agitación violenta la que produce el ruido del trueno que escuchamos; porque este viento sulfuroso sale violentamente de un lugar angosto donde estaba confinado, golpea el aire muy bruscamente, y avanza a una velocidad extraordinaria, igual que la pólvora que sale de un cañón que se ha prendido. Es posible decir aquí que una salitre sutil que siempre se encuentra esparcida en el aire de forma natural, se une al azufre del trueno, y aumenta la fuerza de su agitación y de su acción; de la misma forma que cuando se mezcla la salpetre ${ }^{62}$ con el azufre común, produce un efecto mucho más violento al enrarecerse que cuando está solo.

Este viento sulfuroso del trueno, después de haberse esparcido en el aire durante un tiempo, disminuye poco a poco su agitación; esto se debe a que el trueno es mucho más violento y más peligroso en el momento en que sale de la nube, que cuando ha dejado ya en el aire una parte de sus remolinos y de sus vaivenes: pero finalmente después de tanto brillo, tanto ruido, y tanto estrépito,

58. Se trata de fuentes termales conocidas desde la antigüedad que se encuentran efectivamente en zonas volcánicas: Bourbon-L'Archambault y Vichy (Auvernia), Baraluc-les-Bains (Agde), y Aix-enProvence.

59. Una cal era cualquier óxido metálico en forma de polvo obtenido por sobrecalentamiento de algunas sustancias (metales o minerales) en contacto con el aire (véase la nota siguiente).

60. En alquimia, calcinar era sinónimo de pulverizar por la acción del fuego.

61. Se refiere a los tornados o trombas marinas.

62. Salpetre: nitrato de potasio $\left(\mathrm{KNO}_{3}\right)$, también conocido como espíritu de nitro. 
queda reducido a la nada, y no queda por el lugar por donde pasó más que un olor a azufre similar al del huracán.

En lo que se refiere a las piedras de rayo $^{63}$ de las que el vulgo ve que el trueno está siempre acompañado, su existencia me parece muy dudosa, y soy más propenso en creer que nunca han existido de verdad; no es por tanto absolutamente imposible que los [138] huracanes que ascienden rápidamente hasta las nubes, como se ha dicho, no levanten algunas veces con ellos materias rocosas y minerales, que se debilitan y se unen por el calor, formando lo que se denomina piedra de trueno; pero estas piedras nunca se encuentran en los lugares donde ha caído el trueno: y cuando se encuentra alguna, se haría mejor en creer que provino de un material mineral fundido y formado por el azufre inflamado del trueno en la propia tierra, que pensar que esta piedra se hubo formado en el aire o en las nubes, y arrojada con el trueno.

Resta una dificultad, que es saber cómo el viento sulfuroso que supuse era la materia del trueno podría haberse encendido entre las nubes que están compuestas de agua, y haberse comprimido sin apagarse, porque parece que el agua de las nubes debe haber impedido que se encendiera el azufre, o al menos debió absorberlo mientras ardía.

Para responder a esta dificultad, yo sostengo que el azufre es una sustancia grasa, que no está tan sujeta a la impresión del agua como otras sustancias, y puede inflamase dentro de ella, y arder igual que el alcanfor y muchas otras materias sulfurosas muy excitadas y ardientes. Debe ocurrir, no obstante, que una porción de este azufre se hundió en la gran cantidad de agua que hay en las nubes, y que se apagó con una fuerte detonación, como se produce cuando se lanza al agua alguna materia sólida al rojo vivo; esta detonación contribuye quizás al ruido del trueno; pero otra parte del azufre que era más [139] sutil y está más dispuesta a la agitación, se ha expresado totalmente como fuego. La experiencia que tendré el privilegio de hacer ante los presentes probará mi razonamiento.

Puse en un matraz de capacidad media, y al que le había sido cortado el cuello, tres onzas ${ }^{64}$ de un buen espíritu ${ }^{65}$ de vitriolo ${ }^{66}$ y doce onzas de agua común; apliqué un poco de calor a la mezcla, y añadí en diversas ocasiones una onza u onza y media de limadura de hierro, y entró en ebullición desprendiendo vapores blancos; coloqué una bujía encendida en la boca del matraz, y este vapor ardió, y al mismo

63. Se refiere a los sílex o pedernales, denominados también piedras de chispa, utilizados para hacer fuego en la prehistoria.

64. La onza tenía un valor de 30,593 g (véase la nota 53).

65. Los espíritus, en general, era productos volátiles que se desprendían durante el proceso de la destilación de otras sustancias; también se llamaba espíritu a toda sustancia tenue disuelta en otra sustancia.

66. Espíritu de vitriolo: ácido sulfúrico $\left(\mathrm{H}_{2} \mathrm{SO}_{4}\right)$; también era conocido como espíritu de azufre, aceite de vitriolo, aceite de azufre o ácido vitriólico; químicamente coincidía con el espíritu de alumbre (véase nota 69). 
NICOLAS LÉMERY (1645-1715) Y SU TEORÍA FÍSICO-QUÍMICA SOBRE DIVERSOS FENÓMENOS...

tiempo provocó una fulminación ${ }^{67}$ violenta y estrepitosa; aproximé incluso la bujía encendida varias veces, y emitió fulminaciones parecidas a la primera, durante las cuales el matraz se encuentra completamente lleno de una llama que ha penetrado y se distribuye hasta el fondo del licor, y algunas veces la llama se ha mantenido durante un tiempo bastante considerable en el cuello del matraz.

Hay que observar numerosas circunstancias en esta operación. Primera, la ebullición que empieza cuando se añade limadura de hierro en el licor, proviene de la disolución que se hace de una porción de hierro por el espíritu de vitriolo; pero con el fin de que la ebullición, los vapores y la disolución sean más fuertes, es necesario mezclar agua con el espíritu de vitriolo, en la proporción indicada, porque si este espíritu era puro, y no había sido diluido o embebido por el agua, sus puntas en verdad se fijarán a la limadura de hierro, se unirán y se apretarán unas con otras, de tal suerte que no tendrán agitación independiente para obrar de manera suficiente, y no se producirá la fulminación.

[140] Segunda, se suministra un poco de calor al licor para excitar las puntas del disolvente para que penetre en el hierro y libere los vapores; pero no debe estar demasiado caliente, porque estos vapores saldrían muy rápido, y cuando se metiera la bujía encendida, no haría más que inflamarse en el cuello del matraz, sin fulminación alguna; porque este ruido solo procede del azufre de la materia encendida en el fondo del matraz, que encuentra dificultad para ascender, y hace un gran esfuerzo para destruir el agua y liberarse.

Tercera, necesariamente, el azufre que se excita en vapores y se inflama, tiene que proceder únicamente de la limadura de hierro, porque el agua ni el espíritu de vitriolo, y principalmente el más fuerte, como el que yo he utilizado, no son nada sulfurosos ni inflamables, pero el hierro contiene mucho azufre, como todo el mundo sabe; por lo tanto es el azufre de la limadura de hierro el que ha sido enrarecido y expandido por el espíritu de vitriolo, para ser excitado en un vapor muy susceptible al fuego.

Cuarta, los espíritus ácidos de sal ${ }^{68}$, de azufre y de alumbre ${ }^{69}$ producen en esta operación el mismo efecto que el espíritu de vitriolo: pero el espíritu de nitro ${ }^{70}$ ni el agua fuerte ${ }^{71}$ se excitan hasta la fulminación.

Por lo demás, la operación de la que he venido hablando no se ha ideado solo para la fulminación, sino que es el inicio de una preparación denominada sal o vitriolo de Marte ${ }^{72}$, empleado y apreciado en medicina; así, pues, si se desea sacar provecho de lo que quedaba en el matraz después de la fulminación, habrá

67. El término fulminación, de origen alquimista, indicaba una detonación de gran intensidad.

68. Espíritu de sal: ácido clorhídrico ( $\mathrm{HCl})$.

69. Espíritu de alumbre: ácido sulfúrico $\left(\mathrm{H}_{2} \mathrm{SO}_{4}\right)$.

70. Espíritu de nitro: nitrato de potasio $\left(\mathrm{KNO}_{3}\right)$, conocido también como salpetre.

71. Agua fuerte: ácido nítrico $\left(\mathrm{HNO}_{3}\right)$; a veces también se le daba este nombre al espíritu de vino (etanol, $\mathrm{C}_{2} \mathrm{H}_{6} \mathrm{O}$ ) o a una solución de sosa o soda cáustica (hidróxido de sodio, $\mathrm{NaOH}$ ).

72. Vitriolo de Marte: sulfato de hierro(II) $\left(\mathrm{FeSO}_{4}\right)$. 
que hervirlo, filtrarlo, evaporar el licor filtrado hasta reducirlo [141] en dos tercios o tres cuartos, y dejarlo cristalizar en un lugar fresco: allí aparece el vitriolo de Marte, que se parece mucho en aspecto, color y sabor al vitriolo de Inglaterra ${ }^{73}$; pero es un poco más dulce, y huele más a hierro. Es un excelente aperitivo ${ }^{74}$, a una dosis de seis granos ${ }^{75}$ hasta un escrúpulo ${ }^{76}$ : si se suministra en una dosis mayor, puede producir algunas nauseas, pero no con tanta intensidad como el vitriolo ordinario.

El vitriolo de Marte es propiamente una revivificación del vitriolo natural: porque el espíritu ácido del vitriolo que había sido aislado de su tierra por destilación, penetra por esta operación en los poros del hierro, lo disuelve y le da cuerpo; añado a esto que el hierro contiene una sal vitriólica muy apta para contribuir a la formación de este vitriolo de Marte.

Puse $^{77}$ en una retorta de cerámica ocho onzas de vitriolo de Marte; adapté un gran vaso o recipiente, y realicé la destilación, como habitualmente se hace del vitriolo ordinario, y extraje cinco onzas y cinco dracmas ${ }^{78}$ de un espíritu ácido, transparente, bastante parecido al espíritu de vitriolo común, pero que deja en la lengua un sabor un poco astringente o estíptico: saqué del vaso primero el que estaba separado de la retorta, con un fuerte olor a azufre; este espíritu es adecuado para las pérdidas de sangre, y los malestares de estómago; encontré en la retorta un material muy enrarecido, ligero, muy desmenuzable, rojo, que se disuelve fácilmente en la boca, de un sabor astringente, tirando un poco a lo dulce, y es un estupendo azafrán de Marte aperitivo.

Puse en un crisol al fuego otra porción de vitriolo de Marte cristalizado: el material se [142] fundió, se evaporó mucha flema ${ }^{79}$, y quedó un vitriolo blanco ${ }^{80}$, como sucede cuando se calcina el vitriolo común; arrojé a un fuego vivo este vitriolo blanco, y se volvió rojo como el colcótar ${ }^{81}$. Se puede, así, concluir que el vitriolo de Marte es similar en todo al vitriolo natural ${ }^{82}$.

73. Ambos vitriolos (de Marte y de Inglaterra) eran la misma sustancia.

74. Aperitivo: laxante o purgante.

75. Un grano valía 0,0531 g (véase la nota 53).

76. El escrúpulo, como medida de dosis farmacéutica, tenía una equivalencia a 1,296 g.

77. En estos dos últimos párrafos se describe someramente un proceso de destilación en diferentes fases, o rectificación; véase lo dicho en la Introducción respecto al abandono por parte de Lémery de este último término y la adopción definitiva del primero.

78. Dracma: medida de peso utilizada en farmacia con un valor de $3,888 \mathrm{~g}$.

79. Flema: cualquier fracción acuosa de una destilación; también hacía referencia al agua, como uno de los dos principios pasivos de la alquimia.

80. Cuando Lémery habla aquí de un vitriolo blanco se está refiriendo al color del vitriolo, y no al término alquímico vitriolo blanco, que era en realidad sulfato de cinc $\left(\mathrm{ZnSO}_{4}\right)$, lo que químicamente era imposible de obtener en ese experimento, puesto que el cinc no se encontraba entre las sustancias reaccionantes.

81. Colcótar: pigmento de color rojo formado por peróxido de hierro $\left[\mathrm{Fe}_{2}\left(\mathrm{O}_{2}\right)_{3}\right]$ pulverizado; también se le denomina rojo París.

82. Aunque vitriolo era un término genérico para los sulfatos, habitualmente hacía referencia al sulfato de hierro (II); por eso Lémery concluye que el vitriolo de Marte es similar al vitriolo natural. 
NICOLAS LÉMERY (1645-1715) Y SU TEORÍA FÍSICO-QUÍMICA SOBRE DIVERSOS FENÓMENOS...

\section{BIBLIOGRAFÍA}

AMADOR, Filomena. "Los 'volcanes' de Nicholas Lemery (1645-1715)». Enseñanza de las Ciencias de la Tierra, 2004, 12(3), pp. 253-259.

AMADOR, Filomena. "The causes of 1755 Lisbon earthquakes on Kant". Actas VIII Congreso de la Sociedad Española de Historia de las Ciencias y de las Técnicas (Logroño/2002), 2004, vol. 2, pp. 485-495.

ARISTÓTELES. Los Meteorológicos. Traducido por J. L. Calvo Martínez. Madrid: Alianza, 1996. ARISTÓTELES. Acerca de la generación y la corrupción. Tratados breves de historia natural. Traducido por E. La Croce y A.B. Pajares. Madrid: Gredos, 1987.

ARISTÓTEles (Pseudo-). De Mundo. Traducido por E. S. Forster. Oxford: Oxford University Press, 1914.

Bensaude-Vincent, Bernadette y Blondel, Christine (eds.). Science and spectacle in the European Enlightenment. 1. ${ }^{\mathrm{a}}$ ed. Aldershot: Ashgate, 2008.

Bensaude-Vincent, Bernadette y Stengers, Isabelle. Histoire de la Chimie. 1. ${ }^{\mathrm{a}}$ ed. Paris: La Découverte, 1993. [existe ed. castellana: Historia de la química. Traducido por E. Hidalgo. Madrid: Addison Wesley Iberoamericana, 1997.

BERTOMEU SÁNCEZ, José Ramón. «La revolución química: entre la historia y la memoria». DYNAMIS, Acta Hispanica ad Medicinae Scientiarumque Historiam Illustrandam, 2006, 26, pp. 307-322.

Bertomeu SÁNChez, José Ramón y García Belmar, Antonio. La revolución química: Entre la historia y la memoria. 1. ${ }^{a}$ ed. Valencia: Publicacions de la Universitat de València, 2006.

BEVIS, John (ed.). The history and philosophy of earthquakes, from the remotest to the present time. 1. ${ }^{a}$ ed. London: J. Nourse, 1757.

Blas y Álvarez, Luis. Biografías y descubrimientos químicos. 1. ${ }^{a}$ ed. Madrid: Aguilar, 1947.

BougarD, Michel. "Vers une histoire des sciences «expérimentale»: Analyse de la pratique chimique de Nicolas Lémery (1645-1715)». Chimie nouvelle, 2002, 20(78), pp. 44-49.

Bougard, Michel. La Chimie de Nicolas Lemery. 1. ${ }^{a}$ ed. Turnhout: Brepols, 1999.

Bourzat, Jean Dominique. Lecture contemporaine du Cours de Chymie de Nicolas Lemery. 1. ${ }^{\mathrm{a}}$ ed. Lyon: Cosmogone, 2005.

Boutin, Pierre. "Spectacle en ville: l'expulsion du Dieu vengeur du Volcan de Lémery». En Bertrand, Dominique, Rieutort, Laurent y Thouret, Jean-Claude (eds.). Villes et volcans. 1. ${ }^{\mathrm{a}}$ ed. Clermont-Ferrand: Presses Universitaires Blaise-Pascal, 2009, pp. 175-181.

Bouvet, Maurice. "Les laboratoires parisiens de Nicolas Lémery". Revue d'Histoire de la Pharmacie, 1950, 38. ${ }^{\mathrm{e}}$ année, 126, pp. 24-30.

Boyle, Robert. El químico escéptico. Barcelona: Crítica (trad. castellana 2012), 1661.

BREIDERT, Wolfgang (ed.). Die Erschütterung der vollkommenen Welt. Die Wirkung des Erdbebens von Lissabon im Spiegel europäischer Zeitgenossen. 1. ${ }^{a}$ ed. Darmstadt: Wissenschaftliche Buchgesellschaft, 1994.

Buffon, Georges Louis Leclerc, Conde de. «Preuves de la Théorie de la Terre». En Histoire Naturelle, générale et particulière. 2. ${ }^{a}$ ed. París: Imprimerie Royal, 1744 (ed. 1749), tomo I, Article XVI (Des Volcans \& des Tremblemens de Terre), pp. 502-535. [Existen diferentes ediciones castellanas de esta obra; véase, por ejemplo: «Pruebas de la Teórica de la Tierra». En Historia Natural, general y particular. Traducido por J. Clavijo y Faxardo. Madrid: Viuda de Ibarra, 1786, tomo II, pp. 260-348].

CAP, Paul-Antoine. Études biographiques pour servir à l'bistoire des sciences. Première Série: Chimistes-Naturalistes. 1. ${ }^{\mathrm{a}}$ ed. Paris: Victor Masson, 1857. 
CAPEL, Horacio. "Organicismo, fuego interior y terremotos en la ciencia española del siglo XVIII». GeoCrítica, 1980, 27-28, pp. 5-94.

Carvallo, Sarah. "Chimie et scepticisme: Héritage et ruptures d'une science. Analyse du Chimiste Sceptique, 1661, Robert Boyle». Revue d'Histoire des Sciences, 2002, 55(4), pp. 451-492.

Christie, John R. R. y Golinski, Jan V. "The spreading of the word: new directions in the historiography of chemistry 1600-1800». History of Science, 1982, 20, pp. 235-266.

ClericuzIo, Antonio. Elements, principles and corpuscles. A study of atomism and chemistry in the seventeenth century. $1{ }^{a}$ ed. Dordrecht-Boston: Kluwer, 2000.

ClericuzIO, Antonio. "Teaching chemistry and chemical texbooks in France. From Beguin to Lemery". Science \& Education, 2006, 15(2-4), pp. 335-355.

CLERICUZIO, Antonio. "Sooty empiricks' and natural philosophers: The status of chemistry in the seventeenth century». Science in Context, 2010, 23(3), pp. 329-350.

Crosland, Maurice P. Historical studies in the language of chemistry. $1 .^{a}$ ed. London: Heinemann, 1962.

Dorveaux, Paul. "Apothicaires membres de l'Académie Royale des Sciences. VI. Nicolas Lémery". Revue d'Histoire de la Pharmacie, 1931, 19, pp. 208-219.

DraKe, Ellen Tan. Restless genius. Robert Hooke and his earthly thoughts. 1. ${ }^{a}$ ed. New York: Oxford University Press, 1996.

EKLund, John. The incompleat chymist: Being an essay on the Eighteenth-Century chemist in his laboratory, with a dictionary of obsolete chemical terms of the period. 1. ${ }^{a}$ ed. Washington: Smithsonian Institution Press, 1975.

ENCICLOPEDIA UNIVERSAL Ilustrada Europeo-Americana. Madrid: Espasa-Calpe, 1968, tomo LXIX.

ENCYCLOPÉDIE, ou Dictionnaire raisonné des Sciences, des Art et de Métiers. Paris: Briasson, David, Le Breton \& Durand, 1753, tomo III.

Encyclopédie, ou Dictionnaire raisonné des Sciences, des Art et de Métiers. Neufchastel: Samuel Faulche, 1765, tomo XVII.

Encyclopédie, ou Dictionnaire raisonné des Sciences, des Art et de Métiers. Neufchastel: Samuel Faulche, 1765, tomo XVI.

Folch Jou, Guillermo y Frances CAUSAPE, M. ${ }^{a}$ Carmen. "L'influence de Nicolas Lémery dans la pharmacie espagnole». Veröffentlichungen der Internationalen Gesellschaft für Geschichte der Pharmazie, 1975, 42, pp. 49-54.

FonTENELLE, Bernard Le Bovier de. «Sur les feux souterrains, les tremblemens de terre, le tonnerre, \&c. expliquez chimiquement». Histoire de l'Académie Royale des Sciences, Année M. DCC, avec les Mémoires de Mathématiques et de Physique pour la même année. Ámsterdam: G. Kuyper, 1700 (publicado en 1706), pp. 65-66.

FonTENElLE, Bernard Le Bovier de. "Éloge de M. Lémery». Histoire de l'Académie Royale des Sciences, Année M.DCCXV, avec les Mémoires de Mathématiques et de Physique pour la même année. Paris: Imprimerie Royale, 1715, pp. 73-82 (publicado en 1717) [reproducido en Euvres diverses de M. de Fontenelle. La Haya: Gosse \& Neaulme, tomo III (nouvelle édition, 1729), pp. 186-193].

FranCKOWIAK, Rémi. "La chimie du XVII e siècle: une question de principes". Methodos, Savoirs et Textes, 2008, 8, pp. 1-43.

García Yebra, Valentín. Prólogo. En Metafísica de Aristóteles. Traducido por V. García Yebra. 1. ${ }^{a}$ ed. Madrid: Gredos (ed. trilingüe griego-latín-castellano), 1970, pp. I-LIII. 
GOLINSKI, Jan V. «Science in the Enlightenment, revisited». History of Science, 2011, 49(163), pp. 217-231.

Gran Enciclopedia Larousse. Barcelona: Planeta, 1972, tomo 10.

Guedon, Jean-Claude. «Protestantisme et Chimie. Le milieu intellectuel de Nicolas Lémery». Isis, 1974, 65(2), pp. 212-228.

GuERRINI, Anita. "Chemistry teaching at Oxford and Cambridge, circa 1700». En RATTANSI, Piyo y Clericuzio, Antonio (eds.). Alchemy and chemistry in the $16^{\text {th }}$ and $17^{\text {h }}$ centuries (Proceedings Warburg Colloquium 1989). Dordrecht: Kluwer, 1994, pp. 183-199.

GUIDOBOnI, Emanuela. «Earthquakes, theories from antiquity to 1600». En GOOD, Gregory Allan (ed.). Sciences of the Earth: An encyclopedia of events, people, and phenomena. 1. ${ }^{a}$ ed. New York: Garland, 1998a, vol. I, pp. 197-205.

Guidoboni, Emanuela. «Earthquakes, theories from 1600 to 1800». En GooD, Gregory Allan (ed.). Sciences of the Earth: An encyclopedia of events, people, and phenomena. 1. ${ }^{a}$ ed. New York: Garland, 1998b, vol. I, pp. 205-214.

Guyton de Morveau, Louis B.; Lavoisier, Antoine L.; Berthollet, Claude L. y Fourcroy, Antoine F. de. Método de la nueva nomenclatura química. Traducido por P. Gutiérrez Bueno. Madrid: Antonio de Sancha, 1788 (de la 1. ${ }^{\mathrm{a}}$ ed. francesa 1787).

Hannaway, Owen. "Lémery, Nicolas». En GiluIspie, Charles Coulston (ed.). Dictionary of Scientific Biography. 1. ${ }^{a}$ ed. New York: Charles Scribner, 1981, vol. 8, pp. 172-175.

Hannaway, Owen. The chemists and the word: The didactics origins of chemistry. $1 .^{a}$ ed. Baltimore (MD): Johns Hopkins University Press, 1975.

HERNÁNDEZ MARCOS, Maximiliano. "Un texto de Immanuel Kant sobre las causas de los terremotos (1756)». Cuadernos Dieciochistas, 2005, 6, pp. 215-224.

Hooke, Robert. «Lectures and discourses of earthquakes, and subterraneous eruptions». En WALLER, Richard (ed.). The posthumous works of Robert Hooke. 1. ${ }^{a}$ ed. London: Smith \& Walford (1705), 1668-1700, pp. 277-450 (Discourse No 26/1699, pp. 425-426). [Reproducido en DraKe, 1996, pp. 159-365].

JOLY, Bernard. "À propos d'une prétendue distinction entre la chimie et l'alchimie au XVII ${ }^{\mathrm{e}}$ siècle: Questions d'histoire et de méthode». Revue d'Histoire des Sciences, 2007, 60(1), pp. 167-184.

KANT, Immanuel. "Von den Ursachen der Erderschütterungen bei der Gelegenheit des Unglücks, welches die westlichen Länder von Europa gegen das Ende des vorigen Jahres getroffen hat,. En Kant's Werke. Berlin: G. Reimer (1910), 1756a, tomo I (Vorkritische Schriften I, 1747-1756), pp. 417-427.

KANT, Immanuel. "Geschichte und Naturbeschreibung der merkwürdigsten Vorfälle des Erdbebens, welches an dem Ende des 1755sten Jahres einen großen Theil der Erde erschüttert hat». En Kant's Werke. Berlin: G. Reimer (1910), 1756b, tomo I (Vorkritische Schriften I, 1747-1756), pp. 429-461.

KANT, Immanuel. "Fortgesetzte Betrachtung der seit einiger Zeit wahrgenommenen Erderschütterungen». En Kant's Werke. Berlin: G. Reimer (1910), 1756c, tomo I (Vorkritische Schriften I, 1747-1756), pp. 463-472.

KIM, Mi Gyung. Affinity, that elusive dream. A genealogy of the chemical revolution. 1. ${ }^{\text {a }}$ ed. Cambridge (MA): MIT Press, 2003.

KIRCHER, Athanasius. Mundus subterraneus. 1. ${ }^{a}$ ed. Amsterdam: J. Janssonius, 1665, 2 tomos (en 1 vol.), 346+487 pp. [ed. inglesa (selección de textos): The Volcano's, or burning and fire-vomiting mountains famous in the world. Traductor anónimo. London: John Allen, 1669]. 

NICOLAS LÉMERY (1645-1715) Y SU TEORÍA FÍSICO-QUÍMICA SOBRE DIVERSOS FENÓMENOS...

KOZÁK, Jan y ČERMÁK, Vladimir. Illustrated history of natural disasters. 1. ${ }^{a}$ ed. New York: Springer, 2010

LAFOnT, Olivier. D'Aristote à Lavoisier. Les étapes de la naissance d'une science. 1 a $^{\text {a }}$ ed. Paris: Ellipses, 1994.

LAFOnt, Olivier. "Nicolas Lémery et l'acidité». Revue d'Histoire de la Pharmacie, 2002, $90^{e}$ année, 333, pp. 53-62.

LaIssus, Yves y ToRLaIS, Jean. «Le Jardin du Roi et le Collège Royal dans l'enseignement des sciences au XVIII siècle». En TATON, René (ed.). Enseignement et diffusion des sciences en France au XVIII siècle. 1. ${ }^{a}$ ed. Paris: Hermann, 1964, pp. 259-341.

LARSEN, Svend Erik. "The Lisbon earthquake and the scientific turn in Kant's philosophy». European Review, 2006, 14 (3), pp. 359-367.

LaUdAn, Rachel. From mineralogy to geology. The foundations of a science. Chicago (IL): Chicago University Press, 1987 (2. ${ }^{a}$ ed. 1993).

LEICESTER, Henry Marshall y KLICKSTEIN, Herbert Sidney. A source book in chemistry, 14001900. 1. ${ }^{a}$ ed. New York: MacGraw Hill, 1952.

LÉMERY, Nicolas. Cours de Chymie. 1. ${ }^{a}$ ed. París: Chez l'Autheur, 1675, 578 pp. [trad. castellana: Curso chymico. Traducido por F. Palacios. Madrid: J. Garcia Infançon, (1703 de la 9. ${ }^{a}$ ed. francesa 1697)].

LÉMERY, Nicolas. «Explication physique et chymique des Feux souterrains, des Tremblemens de Terre, des Ouragans, des Eclairs \& du Tonnerre». Histoire de l'Académie Royale des Sciences, Année M. DCC, avec les Mémoires de Mathématiques et de Physique pour la même année. Paris: Jean Boudot, 1700 (publicado en 1703), pp. 101-110.

LÉMERY, Nicolas. «Explication physique et chymique des Feux souterrains, des Tremblemens de Terre, des Ouragans, des Eclairs \& du Tonnerre». Histoire de l'Académie Royale des Sciences, Année M. DCC, avec les Mémoires de Mathématiques et de Physique pour la même année. Amsterdam: Gerard Kuyper, 1700 (publicado en 1706), pp. 131-142.

LISTER, Martin. «Of the nature of earthquakes; more particularly of the origin of matter of them, from the pyrites alone». Philosophical Transactions of the Royal Society of London, 1684, 14 (157), pp. 512-515 (reproducido en BEvIs, 1757, pp. 59-67).

Macquer, Pierre-Joseph. Dictionnaire de Chimie. 1. ${ }^{a}$ ed. Paris: Lacombe, 1766, 2 tomos.

Macquer, Pierre-Joseph. Dictionnaire de Chimie. Paris: 2. ${ }^{a}$ ed. T. Barrois, 1778, 4 tomos.

MeTZger, Hélène. Les doctrines chimiques en France du début du XVIIe à la fin du XVIIIe siècle. 2. ${ }^{\text {a }}$ ed. Paris: Blanchard, 1923 (2 $2^{\text {a }}$ ed. 1969).

NewCOMB, Sally. The world in a crucible. Laboratory practice and geological theory at the beginning of geology. 1. ${ }^{\text {a }}$ ed. Geological Society of America Special Paper, 2009, vol. 449.

NEWman, William R. "What have we learned from the recent historiography of alchemy?" Isis, 2011, 102 (2), pp. 313-321.

Newman, William R. y Principe, Lawrence M. "Alchemy vs. chemistry. The etymological origins of a historiographic mistake». Early Science and Medicine, 1998, 3 (1), pp. 32-65.

Newton, Isaac. Óptica. Traducido por C. Solís. Madrid: Alfaguara (1. ${ }^{a}$ trad. castellana 1977), 1704.

Oeser, Ebhard. "Historical earthquake theories from Aristotle to Kant". Abhandlungen der Geologischen Bundesanstalt, 1992, 48, pp. 11-31.

Oldroyd, David Roger. Thinking about the Earth: A history of ideas in Geology. 1. ${ }^{\text {a }}$ ed. Londres: Athlone, 1996.

OwEn, William. The general theory and phoenomena of earthquakes and volcanoes. 1. ${ }^{\mathrm{a}}$ ed. Londres: W. Owen Bookseller, 1756. 
NICOLAS LÉMERY (1645-1715) Y SU TEORÍA FÍSICO-QUÍMICA SOBRE DIVERSOS FENÓMENOS...

PLinio EL VIejo. Historia Natural. Traducido por F. Hernández. Madrid: Gredos (trad. castellana 1995), c. 77 d. C., vol. I.

POWERS, John Charles. "Ars sine arte: Nicholas Lemery and the end of Alchemy in the Eighteenth century France». Ambix, 1998, 45, pp. 163-189 [reproducido en DeBus, Allen George (ed.). Alchemy and early modern chemistry: Papers form Ambix. Huddersfield: Jeremy Mills, 2004, pp. 511-537].

POWERS, John Charles. Inventing chemistry. Herman Boerhaave and the reform of the chemical arts. 1. ${ }^{a}$ ed. Chicago (IL): Chicago University Press, 2012.

PRINCIPE, Lawrence M. "A revolution nobody noticed? Changes in early eighteenth-century chymistry». En PRINCIPE, Lawrence M. (ed.). New narratives in eighteenth-century chemistry. Contributions from the First Francis Bacon Workshop (21-25 April/2005). 1. ${ }^{a}$ ed. Dordrecht: Springer, 2007, pp. 1-22.

PRINCIPE, Lawrence M. «Transmuting chymistry into chemistry: Eighteenth-Century Chrysopoeia and its repudiation». En BerTomeu-Sánchez, José R.; Burns, Duncan T. y TiegGeLEN, Brigitte van (eds.). Neighbours and territories: The evolving identity of chemistry ( $6^{\text {th }}$ International Conference on the History of Chemistry Proceedings, 28 août-1. er $^{2}$ septembre 2007). Lovaina: Mémosciences, 2008, pp. 21-34.

QuENET, Grégory. Les tremblements de terre aux XVIIe et XVIIIe siècles: La naissance d'un risque. Seysell: Champ Vallon, 2005.

REINHARDT, Oscar y OLDROYD, David Roger. «Kant's theory of earthquakes and volcanic action". Annals of Science, 1983, 40/3, pp. 247-272.

SHUTE, Michael N. "Ancient imagination and seismic disruption». Yale Review, 1979, 69, pp. 55-71.

SÉNECA, Lucio A. Naturales Quaestiones. Traducido por C. Codoñer Merino. Madrid: CSIC (ed. bilingüe, trad. castellana 1979), 62 d. C., 2 vols.

SEQueIros, Leandro. «El Geocosmos teológico de Athanasius Kircher (1601-1680)». Proyección, 2000, XLVII (199), pp. 281-300.

SEqueIros, Leandro. «El Geocosmos de Athanasius Kircher. Una imagen organicista del mundo en las Ciencias de la Naturaleza en el siglo XVII». Llull, Revista de la Sociedad Española de Historia de las Ciencias y de las Técnicas, 2001, 24, pp. 755-807.

SiegFried, Robert. From elements to atoms: A history of chemical composition. $1 .^{a}$ ed. Filadelfia (PA): American Philosophical Society (Transactions, vol. 94, parts 4-6), 2002.

SierRa VAlENTí, Eduardo. "El Geocosmos de Kircher. Una cosmovisión científica del siglo XVII». GeoCrítica, 1981, 33/34, pp. 1-81.

Sigurdsson, Haraldur. Melting the earth. The history of ideas on volcanic eruptions. $1 .^{\mathrm{a}}$ ed. Oxford-New York: Oxford University Press, 1999.

Sousa Dias, José Pédro y Rõcha PITA, João Luis. "L'influence de la pharmacie et de la chimie françaises au Portugal au XVIIIe siècle: Nicolas Lémery». Revue d'Histoire de la Pharmacie, 1994, 41(300), pp. 84-90.

Terreros y PANDO, Esteban de. Diccionario castellano con las voces de ciencias y artes. $1 .^{a}$ ed. Madrid: Viuda de Ibarra, 1786-1793, 4 tomos (ed. facsímile en Madrid: Arco Libros, 1987).

TonneT, Joseph. Notice sur Nicolas Lémery, chimiste. (Mémoire présenté à l'Académie Royale de Rouen, pour le concours de l'an 1838). 1. ${ }^{a}$ ed. Niort: Académie Royale de Rouen, 1840.

WISNIAK, Jaime. "Nicolas Lémery». Revista CENIC, Ciencias Químicas, 2005, 36 (2), pp. 123130. 